\title{
Bioluminescence in deep-sea isidid gorgonians from the Cape Verde archipelago
}

Received: 29 September 2010/ Accepted: 25 February 2011/Published online: 10 March 2011

(C) Springer-Verlag 2011
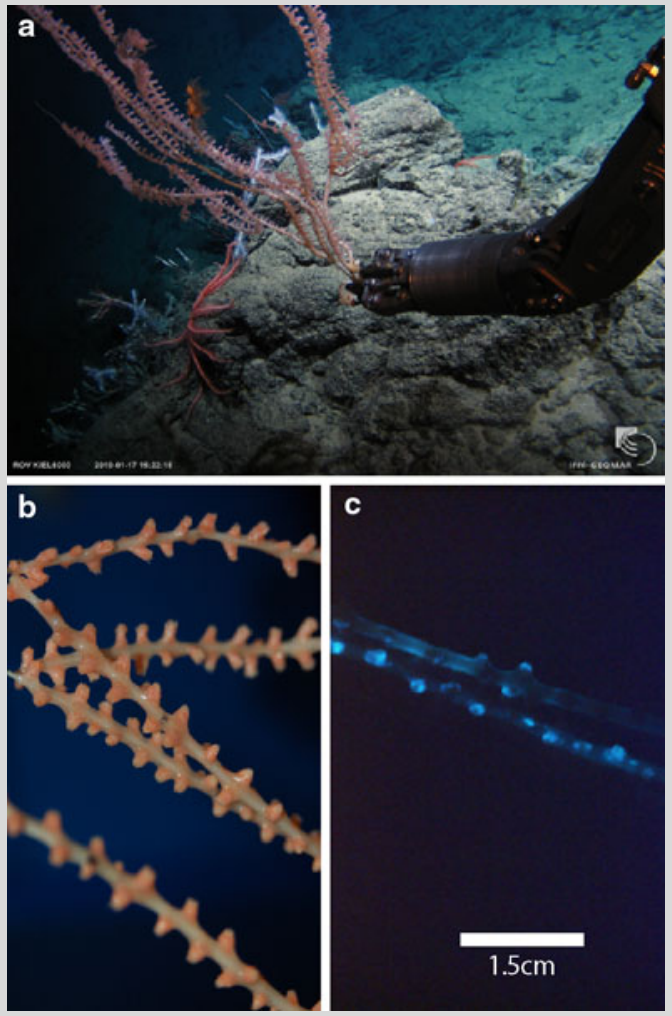

Fig. 1 a ROV sampling of Keratoisis sp. $\sim 3,052 \mathrm{~m}$ depth in the Cape Verde archipelago. b Distal branch of Keratoisis sp. in plain light. c Distal branch of the same colony emitting a strong blue bioluminescence after physical stimulation
Cold-water corals, and in particular numerous gorgonian species, occur abundantly on the deep slopes of the Cape Verde archipelago (Fig. 1a). Among them, the isidid gorgonian genus Keratoisis occurred frequently. A living Keratoisis sp. was ROV collected (KIEL 6000) from $3,052 \mathrm{~m}\left(16^{\circ} 42.3^{\prime} \mathrm{N}, 25^{\circ} 34.9^{\prime} \mathrm{W}\right)$ in the Charles Darwin Volcanic Field (1b) during METEOR cruise M80/3. A strong luminescence was accidentally observed when this bamboo coral arrived on deck in the early evening hours just before sunset. The entire stem and branch tissue showed a dull blue luminescence. Additionally, when touched, it emitted a very strong blue light (Fig. 1c) that persisted for a few seconds. Coral tissue lit up strongest and flash like at the point of stimulation, and the illumination spread in a wave across the coenenchyme of the distal branches. The most intense light emission originated from the non-retractile sclerite-rich feeding polyps and remained visible for several minutes before it slowly faded. This phenomenon could be reproduced several times within hours. Luminescence in octocorals has been observed in the alcyonarian Anthomastus sp., as well as in isidid gorgonians (Isidella, Keratoisis, and Lepidisis), primnoid gorgonians (Primnoisis and Thouarella), and in Iridigorgia and Acanthogorgia (Herring 1987). Muzik (1978) documented bioluminescence in the isidid gorgonian Lepidisis olapa off Hawaii, and Etnoyer (2008) mentioned luminescent capabilities for Isidella tentaculum from the northeast Pacific. Just recently, bioluminescence was reported for Keratoisis flexibilis and for the zoanthid Gerardia sp. from the Gulf of Mexico (http://oceanexplorer.noaa.gov/explorations/09bioluminescence/). Likely due to the scarce availability of direct deep-sea sampling and observation, there are no further Atlantic records for bioluminescence in the Keratoisidinae outside the Gulf of Mexico.

Our additional observations support that bioluminescence in Keratoisis and in other deep-sea gorgonians is rather common and deserves detailed in situ observations.

\section{References}

Etnoyer P (2008) A new species of Isidella bamboo coral (Octocorallia: Alcyonacea: Isididae) from northeast Pacific seamounts. Proc Biol Soc Wash 121:541-553

Herring PJ (1987) Systematic distribution of bioluminescence in living organisms. J Biolumin Chemilumin 1:147-163

Muzik K (1978) A bioluminescent gorgonian, Lepidisis olapa, new species (Coelenterata: Octocorallia) from Hawaii. Bull Mar Sci 28:735-741

J. Raddatz $(\bowtie) \cdot$ W.-C. Dullo · T. Hansteen

IFM-GEOMAR Leibniz-Institute of Marine Sciences at Kiel University, Wischhofstr. 1-3, 24148 Kiel, Germany

e-mail: jraddatz@ifm-geomar.de

M. López Correa

GeoZentrum Nordbayern (GZN), Universität Erlangen-Nürnberg, Erlangen, Germany

A. Rüggeberg

Department of Earth and Environmental Sciences, K. U. Leuven, Celestijnenlaan 200 E, 3001 Heverlee, Belgium
D) व व द

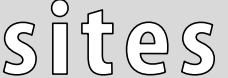
Coral Reefs (2011) 30:579
DOI $10.1007 / \mathrm{s} 00338-011-0743-5$ 